\title{
A CFD study of the transport and fate of airborne droplets in a ventilated office: The role of droplet-droplet interactions
}

\author{
Allan Gomez-Flores ${ }^{1}$, Gukhwa Hwang ${ }^{2}$, Sadia Ilyas ${ }^{2}$, Hyunjung Kim (ه) ${ }^{1,2}$ \\ 1 Department of Environment and Energy, Jeonbuk National University, Jeonju Jeonbuk 54896, Republic of Korea \\ 2 Department of Mineral Resources and Energy Engineering, Jeonbuk National University, Jeonju Jeonbuk 54896, Republic of Korea
}

\begin{abstract}
H I G H L I G H T S
- Coulomb and Lennard-Jones forces were considered for droplet interactions.

- The net droplet interactions were repulsive.

- Repulsive droplet interactions increased the transport of droplets.

- Repulsive droplet interactions significantly modified the fate of droplets.
\end{abstract}

\section{A R T I C L E I N F O}

\section{Article history:}

Received 13 January 2021

Revised 15 May 2021

Accepted 22 May 2021

Available online 20 June 2021

\section{Keywords:}

Droplet interactions

Aerosols

Colloids

CFD

Transport

Fate

\section{G R A P H I C A S T R A C T}

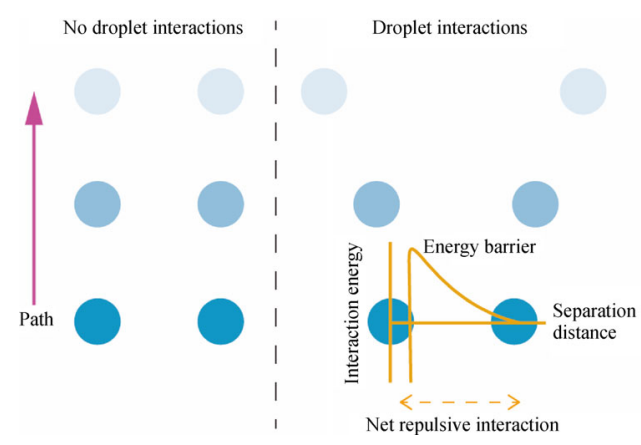

\section{A B S T R A C T}

Previous studies reported that specially designed ventilation systems provide good air quality and safe environment by removing airborne droplets that contain viruses expelled by infected people. These water droplets can be stable in the environment and remain suspended in air for prolonged periods. Encounters between droplets may occur and droplet interactions should be considered. However, the previous studies focused on other physical phenomena (air flow, drag force, evaporation) for droplet transport and neglected droplet interactions. In this work, we used computational fluid dynamics (CFD) to simulate the transport and fate of airborne droplets expelled by an asymptomatic person and considered droplet interactions. Droplet drag with turbulence for prediction of transport and fate of droplets indicated that the turbulence increased the transport of $1 \mu \mathrm{m}$ droplets, whereas it decreased the transport of $50 \mu \mathrm{m}$ droplets. In contrast to only considering drag and turbulence, consideration of droplet interactions tended to increase both the transport and fate. Although the length scale of the office is much larger than the droplet sizes, the droplet interactions, which occurred at the initial stages of release when droplet separation distances were shorter, had a significant effect in droplet fate by considerably manipulating the final locations on surfaces where droplets adhered. Therefore, it is proposed that when an exact prediction of transport and fate is required, especially for high droplet concentrations, the effects of droplet interactions should not be ignored.

(C) Higher Education Press 2021

\section{Introduction}

The recent severe acute respiratory syndrome coronavirus 2 (SARS- $\mathrm{CoV}-2$ ) outbreak in 2019 is a lethal coronavirus and quickly became a pandemic. Other coronavirus pandemics occurred in the past two decades, such as severe acute respiratory syndrome coronavirus (SARS $-\mathrm{CoV}-1$ ) in 2002 and the Middle East respiratory syndrome

$凶$ Corresponding author

E-mail: kshjkim@jbnu.ac.kr coronavirus (MERS $-\mathrm{CoV}$ ) in 2012. Outbreaks of influenza viruses also occurred in the past. Coronaviruses and influenza viruses have stimulated research in various disciplines, including medical sciences (He et al., 2004; Czub et al., 2005; Ma et al., 2014; Wang et al., 2015; Shang et al., 2020; Walls et al., 2020) and civil engineering (Yu et al., 2004; Gao and Niu, 2006; Kao and Yang, 2006; Zhu et al., 2006; Mui et al., 2009; Redrow et al., 2011; Zhu et al., 2012). The civil engineering investigates the indoor air quality in rooms with ventilation because it is important to design ventilation systems that keep a room free from pathogens. Air velocity profiles and particle (pathogen) 
distributions inside a room are reported when indoor air quality is investigated. Particle distributions depend on the air velocity profiles. The particle distributions are important because they show the potential of a pathogen to infect people inside a room and can help to provide guidelines on how to improve the air circulation in the room. The air circulation inside a closed physical space is usually generated by any type of ventilation apparatus or system. Thus, evaluating air velocity profiles is important to conduct air quality studies.

Air velocity profiles inside a room with ventilation are complex due to the different obstacles (e.g., chairs, desks, and people). Velocity profiles can be measured using tracer gas, particle image velocimetry (PIV), stereoscopic particle image velocimetry (SPIV), volumetric particle tracking velocimetry (VPTV), ultrasonic anemometers, or hotwire anemometers (Yan et al., 2009). These techniques can be practically applied to small rooms, few room/ventilation configurations, and few operation parameters of the ventilation system. However, they are unpractical and expensive when bigger spaces and many configurations and operational parameters need to be investigated. Nevertheless, computational fluid dynamics (CFD) offers a more practical and cheaper approach that can be used to calculate the air velocity profiles and particle distributions. CFD modeling is combined, in some practical cases, with the aforementioned experimental techniques to validate the modeling approach.

CFD modeling has been widely used to investigate the transport of airborne pathogens or respiratory droplets (aerosols) inside various ventilated settings: an empty room (Liu and Zhai, 2007), an empty room with a single person (Sun and Ji, 2007; Redrow et al., 2011), a room with two people (Gao and Niu, 2006; Zhu et al., 2006; Mui et al., 2009), an office room with a single person (Park and Chang, 2019), an office room with two people (He et al., 2011), an isolated hospital room (Kao and Yang, 2006), people in a bus cabin (Zhu et al., 2012), an airplane cabin mock - up (Yan et al., 2009), and an apartment complex (Yu et al., 2004). Some studies reported that a displacement ventilation system is better than a mixed ventilation system because it allows more respiratory droplets to exit a room, thereby providing better air quality and reducing infection risks (Gao and Niu, 2006; Sun and Ji, 2007; Mui et al., 2009; Zhu et al., 2012). An increased ventilation velocity improves the air quality because it reduces the droplet concentration inside the room (Yan et al., 2009; He et al., 2011). Furthermore, the parallel directional ventilation contains droplets in an isolated hospital room (Kao and Yang, 2006). The studies report that droplet diameters $>100 \mu \mathrm{m}$ tend to due to gravity, whereas smaller droplets tend to be transported by air streamlines. Additionally, droplet evaporation was included in the modeling. Droplets $<100 \mu \mathrm{m}$ decreased to a constant diameter of $4-10 \mu \mathrm{m}$ due to evaporation in seconds, whereas large droplets only slightly diminished even after some hours
(Sun and Ji, 2007; Redrow et al., 2011).

The SARS $-\mathrm{CoV}-2$ can be transmitted from person to person through droplets that are released to the environment when an infected person coughs, breaths, talks, or sneezes (Liu et al., 2020; Santarpia et al., 2020; Wu and Ping, 2020). SARS $-\mathrm{CoV}-2$ droplets of $1 \mu \mathrm{m}$ (average diameter) (Liu et al., 2020) do withstand evaporation and remain active for several hours on contaminated surfaces (Dowell et al., 2004; Kampf et al., 2020; Ong et al., 2020; van Doremalen et al., 2020). Although droplet transport has been part of previous studies, the droplet fate has not been widely addressed. Because SARS $-\mathrm{CoV}-2$ droplets can remain active in surfaces, their fate must be investigated, especially when a ventilation system can not be improved or replaced, to take necessary actions against its activity. The World Health Organization (WHO) suggests that, during the SARS-CoV-2 pandemic, windows should be opened to provide good ventilation inside a room or office (W.H.O., 2020). However, the efficiency of such practical recommendations has not been widely addressed in CFD modeling of droplet transport in offices. Therefore, using CFD simulations, we investigated the fate (deposition on surfaces) of SARS-CoV-2 droplets inside a ventilated room when the door and windows are closed and opened. Moreover, the previous studies did not include droplet-droplet interactions in their modeling. Submicron droplets (aerosols) can be stable in air currents in the atmosphere, fog and smog are examples of stable aerosols (Squires, 1958; Haas, 1964; Vohra and Nair, 1971). Stability, under proper temperature and pressure conditions, implies that they develop an energetic balance between repulsive and attractive interactions. Interactions between aerosols were reported (Khachatourian and Wistrom, 2001; Isella and Drossinos, 2010). Therefore, we assumed that SARS-CoV-2 droplets behave similarly to rigid spheres (colloids) having attractive and repulsive components and compared the modeling results with and without droplet-droplet interactions.

\section{Materials and methods}

Air velocity profiles inside an office room were simulated using a Low Reynolds Number (LRN) $k-\varepsilon$ turbulence model, the AKN (Abe, Kondoh, and Nagano) model, in COMSOL 5.5 (Stockholm, Sweden). The standard $k-\varepsilon$ model and some of its variations are widely used in previous studies (Gao and Niu, 2006; Zhu et al., 2006; Sun and Ji, 2007; Mui et al., 2009; Yan et al., 2009; He et al., 2011; Redrow et al., 2011; Zhu et al., 2012; Park and Chang, 2019). The AKN $k-\varepsilon$ model provides more accuracy near walls than the standard $k-\varepsilon$ model and other LRN models (Abe et al., 1994). The AKN $k-\varepsilon$ model solves the Navier-Stokes equations for conservation of momentum and the continuity equation for conservation of 
mass. Turbulence effects are modeled using the AKN two-equation $k-\varepsilon$ model with realizability constraints. More details on the governing equations of the turbulence model and their implementation are available in the COMSOL 5.5 user's manual. A summary of the boundary conditions, initial conditions, solver, and other settings used for the simulations are provided in Table S1 of the Supplementary Information (SI). The air flow was solved in a Stationary Study. Figure 1 presents the office configuration used in our study. The office represents an ordinary office room with three desktops, four people, one window, and an old mixing ventilation system. The mechanical ventilation was carried out by a roof ventilator operating at $1 \mathrm{~m} / \mathrm{s}$ (Gao and Niu, 2006; Kao and Yang, 2006; He et al., 2011) without recirculation. The office was assumed to be located in Seoul, Republic of Korea. The temperature in the office was $20^{\circ} \mathrm{C}$, and the wind entering from the windows had an average velocity of $2 \mathrm{~m} / \mathrm{s}$ at the same temperature (Praskievicz and Chang, 2009).

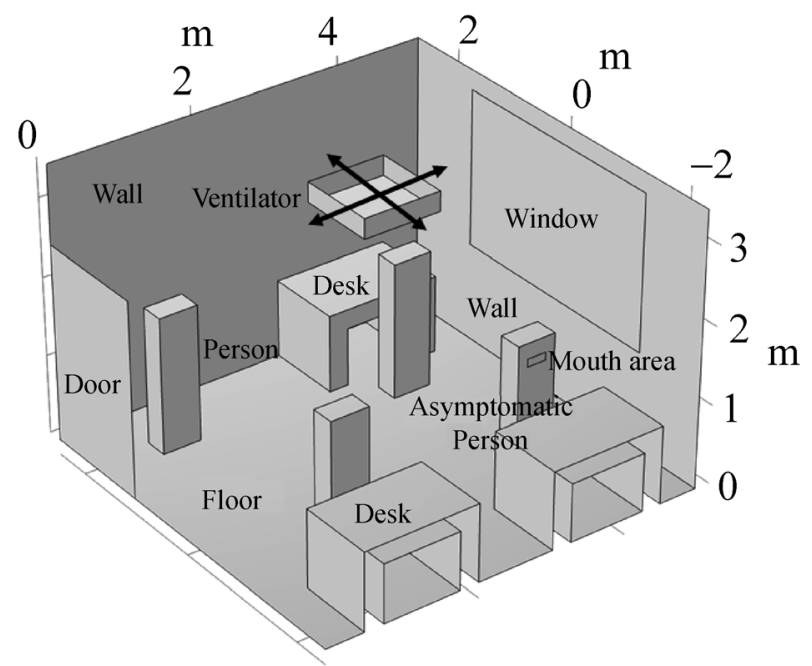

Fig. 1 Diagram of the office used for simulations in Case 1: turned-on ventilator, opened door, and closed window, and Case 2: turned-on ventilator, opened door, and opened window.

Previous studies (Gao and Niu, 2006; Zhu et al., 2006; Sun and Ji, 2007; Mui et al., 2009; Yan et al., 2009; He et al., 2011; Redrow et al., 2011; Zhu et al., 2012; Park and Chang, 2019) assumed that an infected person (symptomatic) indoors spreads a pathogen in droplets by coughing or sneezing at a velocity of around 5-30 m/s. Nevertheless, the SARS $-\mathrm{CoV}-2$ can be spread by an asymptomatic person, even while talking and breathing. It was reported (Chao et al., 2009; Zhang et al., 2015) that breathing droplet velocity is $0.1-1 \mathrm{~m} / \mathrm{s}$ and speaking air velocity $3.6-$ $4.6 \mathrm{~m} / \mathrm{s}$. Thus, we assumed that SARS $-\mathrm{CoV}-2$ droplets are expelled by non-loud talking and breathing of an asymptomatic person in the office with an initial average velocity equal to $2 \mathrm{~m} / \mathrm{s}$. Droplet concentration after coughing is typically less than $10^{8}$ particles $/ \mathrm{m}^{3}$ (Zhu et al., 2006; Gao et al., 2008), total droplet numbers as low as $5 \times 10^{3}-1 \times 10^{4}$ particles were simulated ( $\mathrm{Zhu}$ et al., 2006; Sun and Ji, 2007). It was reported (Asadi et al., 2019) that 1-50 droplets/second were released with speaking loudness using an aerodynamic particle sizer for measurements. Moreover, using a light scattering technique for measurements, it was reported (Stadnytskyi et al., 2020) that loud speaking generated at least 17 virus - containing droplets/second that remained airborne for more than $8 \mathrm{~min}$. We are aware that droplet expelling is characterized by concentration and kinetics. Nevertheless, due to computational limitations, in our simulations we assumed that the person expelled 25 droplets at 0 and $10 \mathrm{~s}$. For each expelling time, initial particle positions were different; this is, a random mesh element on the face boundary was selected for each particle with probability proportional to the element size. Next, random coordinates were selected within the element, particles were placed at the coordinates and released. For any simulation run, the same initial positions in each time were used. The recirculation of droplets from the ventilation system was not considered. Two average droplet diameters $d_{p}$ were assumed, $1 \mu \mathrm{m}$ (Liu et al., 2020) and $50 \mu \mathrm{m}$ (Xie et al., 2009), which are in the range of expiratory aerosols (Gao et al., 2008; Asadi et al., 2020; Stadnytskyi et al., 2020); constant density $\rho_{p}$ of $1000 \mathrm{~kg} / \mathrm{m}^{3}$ (Mui et al., 2009) and charge $Z_{p}$ of $-30 \mathrm{mV}$ (Hagenaars et al., 2009) were also assumed. The effects of droplet evaporation were not considered in the modeling because bigger droplets rapidly evaporate to smaller sizes, which are constant in longer periods. In other words, the time scale of the evaporation (fraction of seconds) is much shorter compared to the time scale of airflow and particle movements (Gao et al., 2008; Drossinos and Stilianakis, 2020).

The transport of droplets was simulated for $600 \mathrm{~s}$ using the Particle Tracing Module in COMSOL 5.5, and the droplet adhesion (fate) onto the surfaces was also quantified. The particle transport and fate were solved in a time-dependent study by using the air flow from the Stationary study. Drag and gravity forces acting on the particles were considered in the simulation. The drag force $\left(F_{D}\right)$ was based on the Schiller-Naumann drag, considering a discrete random walk caused by $k$ and $\varepsilon$ (Eq. (1)):

$$
\begin{gathered}
F_{D}=\frac{1}{\tau_{p}} m_{p}\left[\left(\mathrm{u}+\mathrm{u}_{\mathrm{f}}\right)-\mathrm{v}\right] \\
\tau_{p}=\frac{4 \rho_{p} d_{p}^{2}}{3 \mu C_{D} R e_{p}}
\end{gathered}
$$

where $m_{p}$ is the particle mass, $\mathrm{u}$ is the averaged air velocity, $\mathrm{u}_{\mathrm{f}}$ is the air velocity, $\mathrm{v}$ is the particle velocity. The particle velocity response time $\tau_{p}$ depends on $\rho_{p}, d_{p}$, the dynamic viscosity of air $\mu$, the drag coefficient $C_{D}$, and the particle Reynolds number $R e_{p}$. It has to be noticed that the motion of droplets in air followed Newton's second law. In other 
words, the force on a droplet is equal to the time derivative of its linear momentum, e.g. for constant mass $\frac{d}{d t}\left(m_{p} \mathrm{v}\right)=F_{D}$. Continuous random walk in isotropic inhomogeneous turbulence was considered as using a normalized Langevin equation with a drift correction term (Thomson, 1987; Dehbi, 2008) as follows (Eq. (2)):

$$
\begin{gathered}
\mathrm{d}\left(\frac{\mathrm{u}_{\mathrm{f}}}{\mathrm{u}_{\mathrm{rms}}}\right)=-\left(\frac{\mathrm{u}_{\mathrm{f}}}{\mathrm{u}_{\mathrm{rms}}}\right) \frac{\mathrm{d} t}{\tau_{L}}+\xi \sqrt{\frac{2 d t}{\tau_{L}}}+\frac{\mathrm{d} k}{3 \mathrm{u}_{\mathrm{rms}} d x} \cdot \frac{\mathrm{d} t}{1+S t} \\
\tau_{L}=\frac{C_{L} k}{\varepsilon}, S t=\frac{\tau_{p}}{\tau_{L}}, \mathrm{u}_{\mathrm{rms}}=\sqrt{\frac{2 k}{3}}
\end{gathered}
$$

where $u_{\mathrm{rms}}$ is the turbulent air velocity perturbation, $\tau_{L}$ is the Lagrangian time scale, $C_{L}$ is the Lagrangian time scale coefficient of 0.2 , and $\xi$ is a vector-valued Weiner process with Gaussian random numbers with zero mean and variance $d t$ (Thomson, 1987), $\tau_{L}$ is the Lagrangian time scale, and $S t$ is the particle Stokes number.

Velocity corrections near the wall were made when $y^{+}<100$. Anisotropic turbulence (Dehbi, 2008) in boundary layers was considered by including perturbations in the streamwise $(1=$ parallel), spanwise $(2=$ orthogonal to streamwise and normal), and wall normal (3) directions at the position of each particle. The normalized Langevin equations in the three directions, respectively, are (Eqs. (3)-(5)):

$$
\begin{gathered}
\mathrm{d}\left(\frac{\mathrm{u}_{\mathrm{f} 1}}{\mathrm{u}_{\mathrm{rms} 1}}\right)=-\left(\frac{\mathrm{u}_{\mathrm{f} 1}}{\mathrm{u}_{\mathrm{rms} 1}}\right) \frac{\mathrm{d} t}{\tau_{L}}+\xi_{1} \sqrt{\frac{2 \mathrm{~d} t}{\tau_{L}}} \\
+\frac{d\left(\overline{\mathrm{u}_{\mathrm{f} 1} \mathrm{u}_{\mathrm{f} 2} / \mathrm{u}_{\mathrm{rms} 2}}\right)}{d x_{3}} \cdot \frac{\mathrm{d} t}{1+S t} \\
\mathrm{~d}\left(\frac{\mathrm{u}_{\mathrm{f} 2}}{\mathrm{u}_{\mathrm{rms} 2}}\right)=-\left(\frac{\mathrm{u}_{\mathrm{f} 2}}{\mathrm{u}_{\mathrm{rms} 2}}\right) \frac{d t}{\tau_{L}}+\xi_{2} \sqrt{\frac{2 \mathrm{~d} t}{\tau_{L}}}+\frac{d \mathrm{u}_{\mathrm{rms} 2}}{d x_{3}} \cdot \frac{\mathrm{d} t}{1+S t} \\
\mathrm{~d}\left(\frac{\mathrm{u}_{\mathrm{f} 3}}{\mathrm{u}_{\mathrm{rms} 3}}\right)=-\left(\frac{\mathrm{u}_{\mathrm{f} 3}}{\mathrm{u}_{\mathrm{rms} 3}}\right) \frac{\mathrm{d} t}{\tau_{L}}+\xi_{3} \sqrt{\frac{2 \mathrm{~d} t}{\tau_{L}}}
\end{gathered}
$$

where $x_{3}$ is the wall normal direction, $\mathrm{u}_{\mathrm{rms} 1,2,3}$ and $\tau_{L}$ are:

$$
\begin{gathered}
\mathrm{u}_{\mathrm{rms} 1}^{+}=\frac{\mathrm{u}_{\mathrm{rms} 1}}{u^{*}}=\frac{0.4 y^{+}}{1+0.0239\left(y^{+}\right)^{1.496}} \\
\mathrm{u}_{\mathrm{rms} 2}^{+}=\frac{\mathrm{u}_{\mathrm{rms} 2}}{u^{*}}=\frac{0.0116\left(y^{+}\right)^{2}}{1+0.203 y^{+}+0.00140\left(y^{+}\right)^{2.421}} \\
\mathrm{u}_{\mathrm{rms} 3}^{+}=\frac{\mathrm{u}_{\mathrm{rms} 3}}{u^{*}}=\frac{0.19 y^{+}}{1+0.0361\left(y^{+}\right)^{1.322}}
\end{gathered}
$$

where $u^{*}$ is the friction air velocity,

$$
\tau_{L}= \begin{cases}\frac{10 \rho \mu}{u^{*}} & y^{+} \leqslant 5 \\ \frac{\rho \mu}{\left(u^{*}\right)^{2}}\left[7.122+0.5731 y^{+}\right. & \\ \left.-0.00129\left(y^{+}\right)^{2}\right] & 5<y^{+} \leqslant 100\end{cases}
$$

Some studies (Kao and Yang, 2006; Liu and Zhai, 2007; Gao et al., 2008; Mui et al., 2009; Yan et al., 2009; He et al., 2011; Zhu et al., 2012) used a discrete approach for particle random walk and did not make corrections to turbulence near walls. Conversely, our study continuously models turbulence effects through time and, similarly to our study, there are studies (Matida et al., 2004; Minier, 2015; Mofakham and Ahmadi, 2020) that made wall corrections to ensure that small particles behave as fluid particles, e. g. simulations exhibit sporadic drifts toward a wall. Additionally, the Coulomb force $\left(F_{C}[\mathrm{~N}]\right)$ and Lennard-Jones force $\left(F_{L J}[\mathrm{~N}]\right)$ were the droplet-droplet interactions implemented in our study. $F_{C}$ on particle $i$ in a system of $N$ particles assuming constant surface charge distribution can be defined as Eq. (6) (Khachatourian and Wistrom, 2001):

$$
F_{C}=\frac{\left(2 \pi \varepsilon_{0} d_{p} Z_{p}\right)^{2}}{4 \pi \varepsilon_{0}} \cdot \sum_{j=1}^{N} \frac{1}{|r|^{2}} \frac{r}{|r|}
$$

where $\varepsilon_{0}$ is the permittivity of vacuum $[\mathrm{F} / \mathrm{m}], r=r_{i}-r_{j}[\mathrm{~m}]$ where $r_{i}$ is position vector of the $i^{\text {th }}$ particle [m] and $r_{j}$ is position vector of the $j^{\text {th }}$ particle [m], $F_{C}$ is repulsive for particles with the same charge. $F_{L J}$ consists of two parts, an attractive part (van der Waals) and repulsive part (Born repulsion) (Eq. (7)) (Isella and Drossinos, 2010):

$$
\begin{gathered}
F_{L J, 1}=-\frac{s}{6} \cdot \sum_{j=1}^{N} \frac{1}{|r|}\left\{\ln \left[\frac{|r|^{2}-d_{p}^{2}}{|r|^{2}}\right]\right. \\
\left.\quad+\frac{d_{p}^{2}}{|r|^{2}-d_{p}^{2}}+\frac{d_{p}^{2}}{|r|^{2}}\right\} \frac{r}{|r|} \\
F_{L J, 2}=\frac{s \sigma_{L J}^{6}}{2520} \cdot \sum_{j=1}^{N} \frac{1}{|r|^{2}}\left\{d _ { p } ^ { 2 } \left[\frac{0.5}{\left(|r|-d_{p}\right)^{7}}\right.\right. \\
\left.+\frac{0.5}{\left(|r|+d_{p}\right)^{7}}+\frac{1}{|r|^{7}}\right] \\
-\frac{d_{p}}{3}\left[\frac{1}{\left(|r|-d_{p}\right)^{6}}-\frac{1}{\left(|r|+d_{p}\right)^{6}}\right] \\
\left.-\frac{1}{15}\left[-\frac{1}{\left(|r|-d_{p}\right)^{5}}-\frac{1}{\left(|r|+d_{p}\right)^{5}}+\frac{2}{|r|^{5}}\right]\right\} \frac{r}{|r|}
\end{gathered}
$$


where $s[\mathrm{~J}]$ is the interaction strength (Hamaker constant) assumed as $1 \times 10^{-20} \mathrm{~J}$ (Achebe and Omenyi, 2013; Gentile et al., 2018), $\sigma_{L J}$ is distance of closest approach assumed as $0.6 \mathrm{~nm}$. Additionally, $F_{C}$ and $F_{L J}$ were truncated to zero when $r=0.9 d_{p}$.

Two cases were considered for the modeling, Case 1: turned - on ventilator, opened door and closed window and Case 2: turned-on ventilator, opened door and opened window. The mesh of the office in the CFD simulations for Case 1 consisted of a total of 906514 elements, which had a higher resolution on the walls. The mesh had an average element quality of 0.6712 and a minimum element quality of 0.09323 (the qualities are based on skewness). The mesh for Case 2 consisted of a total of 899271 elements, an average quality of 0.6694 , and a minimum quality of 0.08974 . The mesh resolution was tested for Case 1 based on the changes of $\varepsilon$ and the results are provided in Fig. S1 of the SI. It is known that $k-\varepsilon$ models can predict average flows but have trouble in predicting swirl flows and $\varepsilon$ (Joshi et al., 2011; Katopodes, 2019). The limitations can be avoided by using Large Eddy Simulations but at higher computational cost. Moreover, current literature does not tend to provide experimental measurements of $\varepsilon$ in ventilated rooms. Thus, $\varepsilon$ and $\eta$ are better indicators for mesh acceptability when turbulence is modeled using $k-\varepsilon$ models. Several studies (Kao and Yang, 2006; Zhu et al., 2006; Sun and Ji, 2007; Gao et al., 2008; Mui et al., 2009; Yan et al., 2009; He et al., 2011; Redrow et al., 2011; Zhu et al., 2012; Park and Chang, 2019) have not properly addressed this issue because mesh tests for $\varepsilon$ or $\eta$ were not provided. Figure S1 of the SI shows that $\varepsilon$ tends to increase, especially near walls, as the mesh resolution increases. Thus, the highest mesh resolutions mentioned above were used for simulations. Figure S2 of the SI presents the wall lift - off $\left(y^{+}\right)$in viscous units for Case 1 according to mesh resolution. Although, the limit of $y^{+}$ depends on the turbulent Reynolds number of the system, for many practical applications it could be lower than one hundred (Gao and Niu, 2006). At the walls, $y^{+}$values are $<60$ for the highest mesh resolution indicating acceptable mesh resolution for simulations.

Furthermore, substantial number of studies (Kao and Yang, 2006; Liu and Zhai, 2007; Gao et al., 2008; Mui et al., 2009; Yan et al., 2009; He et al., 2011; Zhu et al., 2012) did not consider the effects of $\varepsilon$ on particle drag while much smaller number of studies did (Zhu et al., 2006; Sun and Ji, 2007; Redrow et al., 2011; Park and Chang, 2019) but without further justification. For the mesh resolution used in our study (MESH 1), the Kolmogorov's length scale $(\eta)$ was $0.4-1.8 \mathrm{~mm}$ (Fig. S3 of the SI). Particles of diameter $\leqslant 10 \eta(\leqslant 4-18 \mathrm{~mm})$ are mainly affected by dissipative - subrange eddies (Nguyen et al., 2016). Accordingly, the assumed droplet diameter of $1 \mu \mathrm{m}$ and $50 \mu \mathrm{m}$ can be affected by $\varepsilon$ resolved in our study at the smallest scales of turbulence. Thus, $F_{D}, F_{C}$ and $F_{L J}$ are affected by $\varepsilon$. For example, a droplet at certain spatial position can be moved by an eddy of certain size to a distance equal to that eddy size influencing its spatial distribution. Therefore, the following approaches were taken in the study: i) drag without $\varepsilon$ and no dropletdroplet interactions, ii) drag with $\varepsilon$ effects and no droplet-droplet interactions, and iii) drag with $\varepsilon$ and droplet-droplet interactions.

\section{Results and discussion}

\subsection{Air dynamics and turbulence inside the office}

Figure 2 presents the velocity magnitudes and fluxes of air inside the office. The air flow was different for each case. Case 1 had the lowest velocities, whereas Case 2 the highest. The air velocities were lower when the window was closed compared with those when it was opened because the ventilation alone covered small volumes. Arrow fluxes indicated that considerable air recirculation occurred in the office center and sides when the window was closed. Conversely, air recirculation inside the office considerably decreased when the window was opened compared with that than when it was closed because the air current occurring in larger volumes directed most of the air flow to the opposite side of the office. Nevertheless, there was a small recirculation at the wall next to the door because the wall redirected the air flow. The air current from the window followed the path along the side where it entered from the opened window; although it tended to slightly deviate to the side of the door. Thus, opening the door and window seemed to considerably reduce the air recirculation while causing recirculation in part of the office where the asymptomatic person was located.

Figure 3 presents $\varepsilon$ inside the office. In overall, $\varepsilon$ for Case 1 was much smaller than for Case 2 because in Case 1 there was no strong air current coming from the window. Case 2 generated higher $\varepsilon$ in the free path and near the walls due to the strong air current. It should be mentioned that $\varepsilon$ also occurred on all walls (surfaces) but some walls were not plotted for easy representation. For case 2, $\varepsilon$ was higher near the door due to the higher velocities (Fig. 2) achieved in that region. Figure 3 indicates that $\varepsilon$ was always present and, thus, its effects on the droplets should not be ignored in any case.

\subsection{Transport and fate of droplets without particle interac- tions}

For the purposes of this study, transport is defined as the traveling distance of droplets and fate is the sticking of droplets on a surface. A low transport means that droplets traveled a short distance from the release boundary (mouth area in Fig. 1) or remained inside the office and a high transport means that droplets traveled distances to exit the office. Similarly, a limited fate means that droplets 


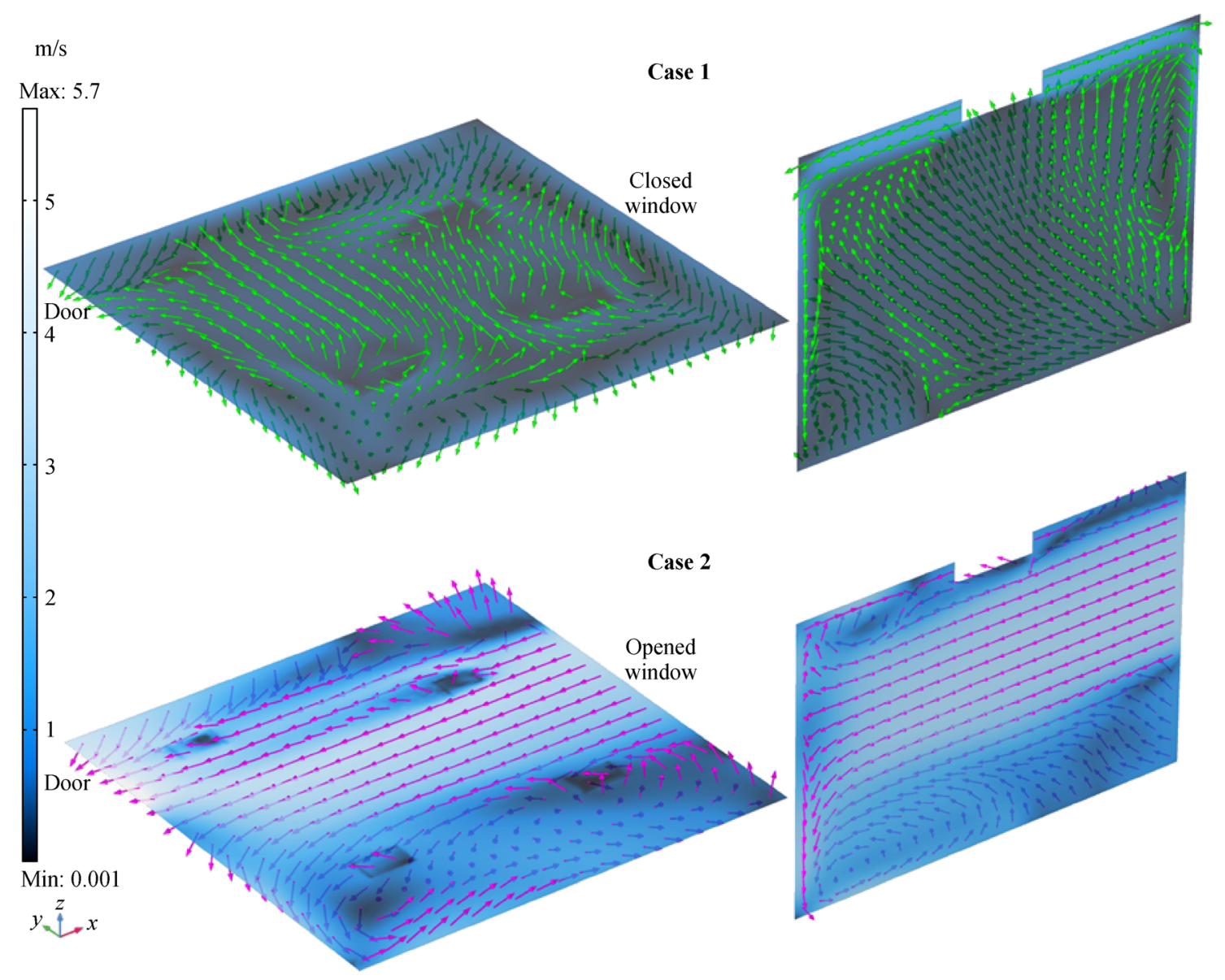

Fig. 2 Air velocity magnitude $(\mathrm{m} / \mathrm{s})$ and arrow flux for Case 1: turned-on ventilator, opened door, and closed window, and Case 2: turned-on ventilator, opened door, and opened window. The planes crossed the central point of the office.

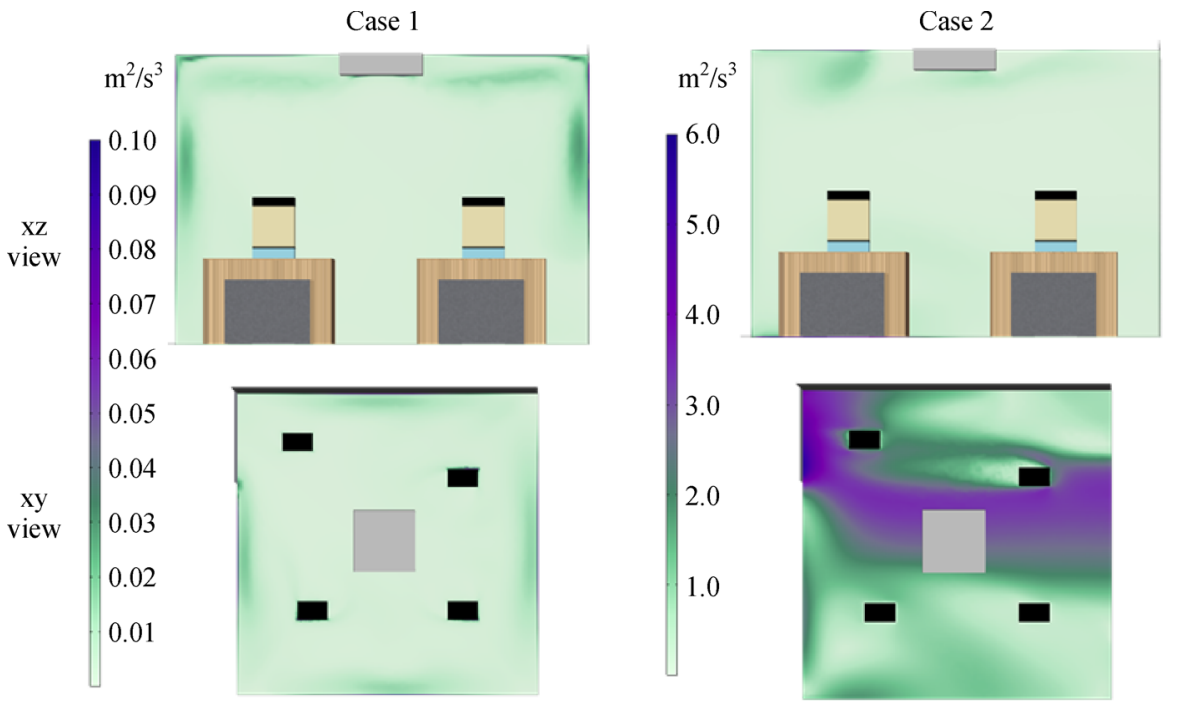

Fig. 3 Turbulent energy dissipation $\left(\varepsilon, \mathrm{m}^{2} / \mathrm{s}^{3}\right)$ for Case 1: turned-on ventilator, opened door, and closed window, and Case 2: turned-on ventilator, opened door, and opened window. 
deposited in few surfaces and a wide fate means that droplets deposited on several surfaces, including their final location on the surfaces and the office.

Figure 4 presents the transport and fate of $1 \mu \mathrm{m}$ droplets according to modeling approach at $600 \mathrm{~s}$ of simulation. For a given modeling approach, Fig. 4 indicates that $F_{D}$ did not have an effect on droplet transport, whereas inclusion of $\varepsilon$ in $F_{D}$ increased the droplet transport from the release boundary. In detail, Table 1 shows that more droplets exited the office through the door but had a limited fate. Furthermore, an opened window generated a higher droplet transport and more droplets exited the office. This suggests that for $1 \mu \mathrm{m}$ droplets, the air quality tended to improve when the window was opened because more droplets exited the office over time. Nevertheless, a higher transport implies that more particles moved inside the office along air currents increasing the risk of droplet contact with surfaces. This was in agreement with Fig. 4 and Table 1 that indicated that some droplets stick on other surfaces.

Figure 5 presents the transport and fate of $50 \mu \mathrm{m}$ droplets according to modeling approach at $600 \mathrm{~s}$ of simulation. For a given modeling approach, Fig. 5 indicates that $F_{D}$ had a significant effect on droplet transport, especially when the window was opened. The increased droplet transport may increase the risk of droplet contact. In detail, Table 1 indicates that some droplets stick on the floor when the window was closed, whereas all droplets exited the office when the window was opened. Conversely, inclusion of $\varepsilon$ in $F_{D}$ decreased the droplet transport because more droplets remained inside the office and generated a wider fate because droplets stick to more surfaces (Fig. 5 and Table 1). Additionally, an opened window did not promote a cleaner office but manipulated the droplet fate by primarily changing the surfaces where droplets stick. Although $F_{D}$ increased due to stronger air currents, droplets tended to end toward the right side of the office where recirculation below the window occurred (Fig. 5).

Figures 4 and 5 indicate that the modeling with $\varepsilon$ (without droplet-droplet interactions) increased the transport of $1 \mu \mathrm{m}$ droplets but decreased the transport and generated a wider fate of $50 \mu \mathrm{m}$ droplets. Regarding the fate, spatial locations of the droplets inside the office were manipulated. The droplets tended to be more dispersed inside the office because $\varepsilon$ increased the relative velocity between air and droplets (Eq. (1)). This increased $F_{D}$ on droplets, especially for $50 \mu \mathrm{m}$ droplets, and the distance that the droplets could travel along air currents. In addition, droplets tended to remain in the face area of the asymptomatic person due to $\varepsilon$. Consequently, the (ii) drag with $\varepsilon$ and no droplet interactions predicted more

Droplet diameter of $1 \mu \mathrm{m}$ and time of $600 \mathrm{~s}$

(i) Drag without $\varepsilon$ and no interactions
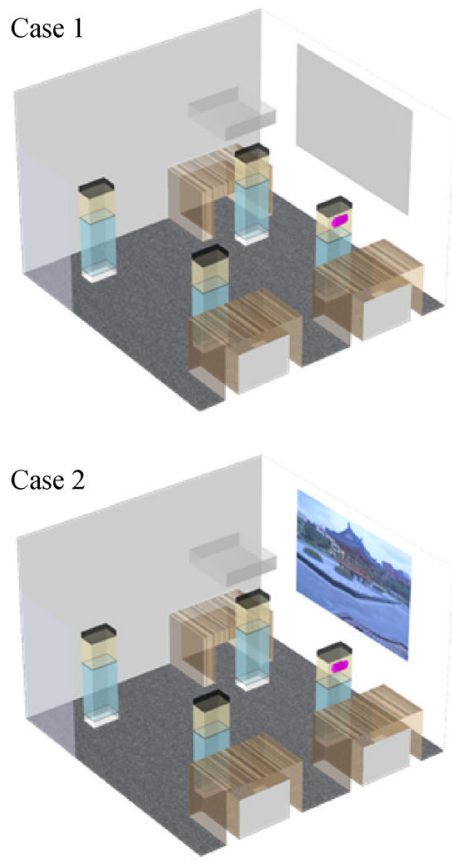

(ii) Drag with $\varepsilon$ and no interactions
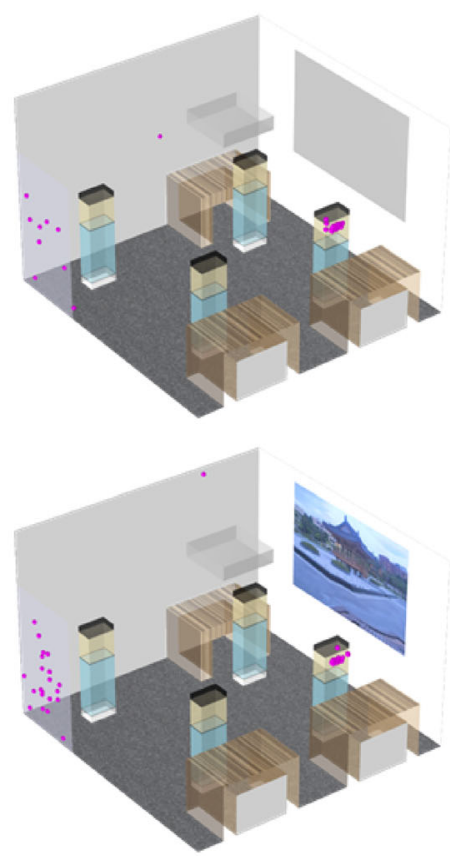

(iii) Drag with $\varepsilon$ and droplet interactions
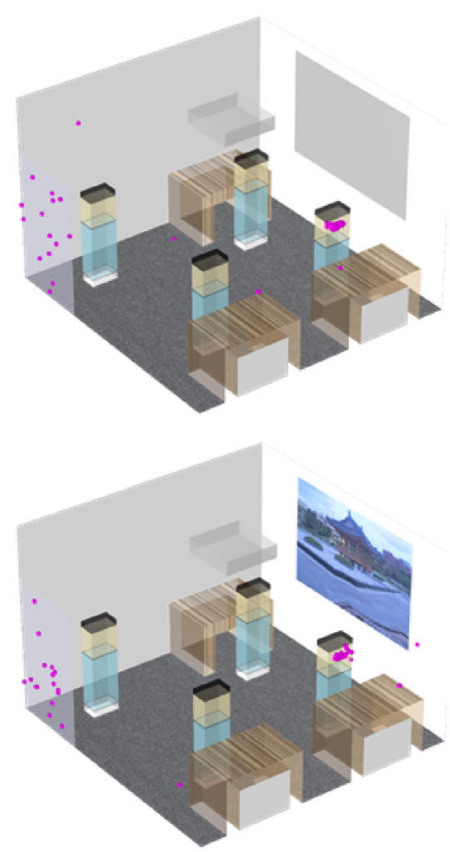

Fig. 4 Fate of $1 \mu \mathrm{m}$ droplets at $600 \mathrm{~s}$ of simulation for Case 1: turned-on ventilator, opened door, and closed window, and Case 2: turned-on ventilator, opened door, and opened window according to modeling approach: (i) drag without $\varepsilon$ and no droplet-droplet interactions, (ii) drag with $\varepsilon$ and no droplet-droplet interactions, (iii) drag with $\varepsilon$ and droplet-droplet interactions. The particles were enlarged for better representation. 
Table 1 Sum of the number of droplets adhered to relevant surfaces in the office room during $600 \mathrm{~s}$ of simulation according to modeling approach for Case 1 (turned - on ventilator, opened door, and closed window) and Case 2 (turned - on ventilator, opened door, and opened window). 25 droplets were released at 0 and $10 \mathrm{~s}$ for a total of 50 droplets

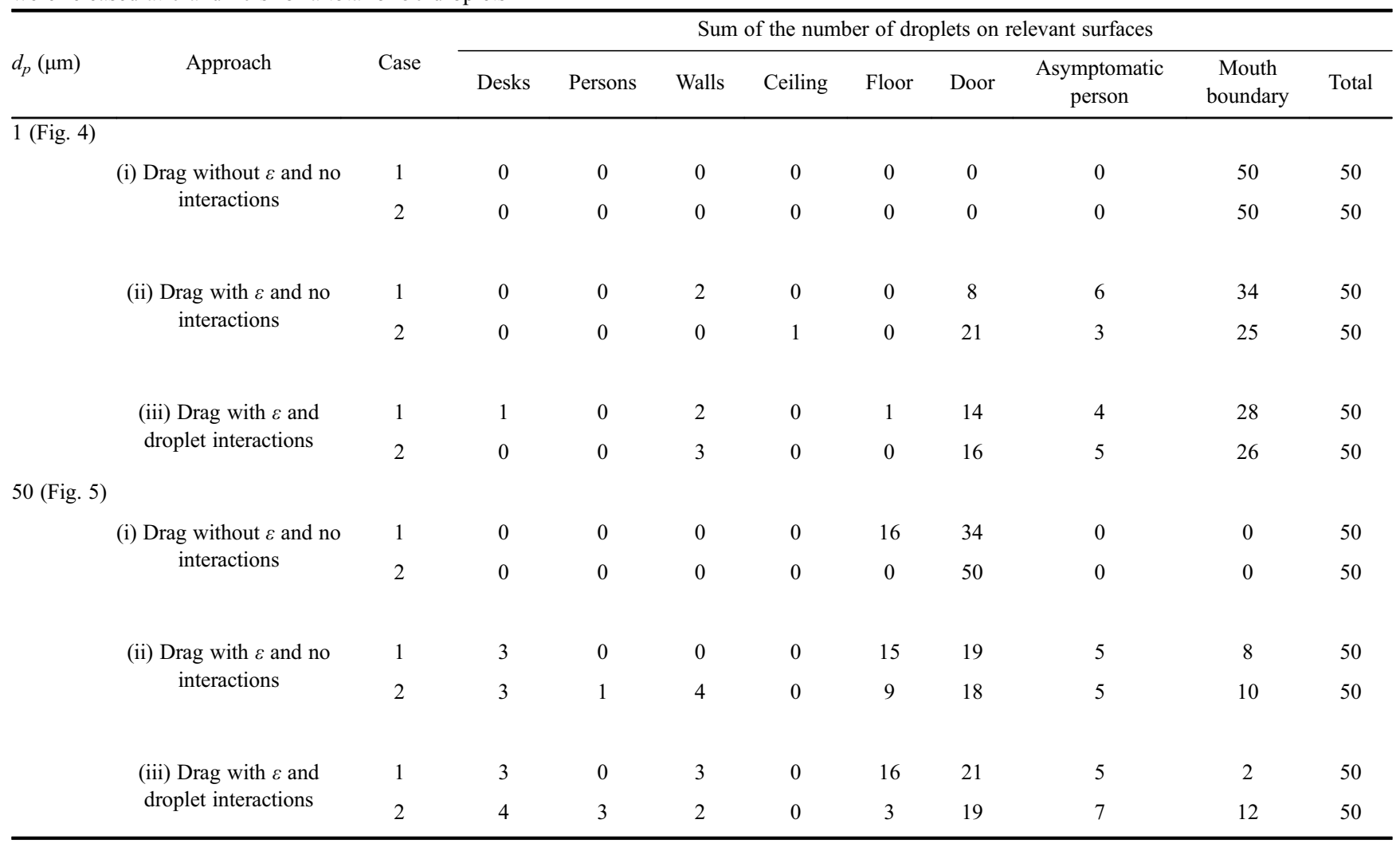

particle contamination than the (i) drag without $\varepsilon$ and no droplet interactions. Although it is not clear which case is the best for avoiding infections, Case 1 was potentially the best because in this case more droplets stick on the floor avoiding contact with people (Table 1). Accordingly, less contact with people in Case 1 produced safer conditions because it was reported (Stadnytskyi et al., 2020) that the probability that a $1 \mu \mathrm{m}$ droplet contains a viron is $0.01 \%$, while that of a $10 \mu \mathrm{m}$ is $0.37 \%$.

\subsection{Transport and fate of droplets with particle interactions}

Figures 4 and 5 present the transport and fate of $1 \mu \mathrm{m}$ and $50 \mu \mathrm{m}$ droplets, respectively, according to modeling approach at $600 \mathrm{~s}$ of simulation. Figures 4 and 5 indicate that the transport and fate of the droplets further changed due to the implementation of droplet-droplet interactions. In detail, the implementation of droplet interactions changed the final locations of droplets inside the office, the droplets tended to be more spread.

For Case 1 (closed window), droplet interactions increased the droplet transport and generated a wider fate for both droplet sizes as seen in Table 1 . For $1 \mu \mathrm{m}$ droplets, Fig. 4 and Table 1 indicate that $12 \%$ more droplets tended to exit through the door when droplet interactions were considered. In contrast, for $50 \mu \mathrm{m}$ droplets, Fig. 5 and Table 1 indicate that only $4 \%$ less droplets exited through the door.

Figure 6 presents the droplet interaction profiles, the forces were converted to $\mathrm{kT}$ units and plotted as a function of droplet-droplet separation distance. The following convention is usually adopted in colloid science, a repulsive interaction has a positive sign and an attractive one has a negative sign. Accordingly, Fig. 6 indicates that the Coulomb interaction was repulsive because of the negative charge of the droplets. The attractive part of the Lennard-Jones interaction operated at long distances, while the repulsive part at short distances. The magnitude of the interactions increased with droplet size; this trend is also reported in the literature (Gomez-Flores et al., 2020). Thus, $50 \mu \mathrm{m}$ droplets experienced the most net repulsive interactions. When the particle interactions have an energy barrier that is low enough, the net interactions can become strongly attractive. The energy barrier can be overcome by the e. g. particle kinetic energy (velocity) and fall in a deep primary minimum of strong attraction.

Nevertheless, an additional simulation in Fig. 7 suggests that the energy barrier was not overcame and the droplet interactions remained repulsive. In detail, Fig. 7 presents a simulation that indicates that when the droplets are close in 
Droplet diameter of $50 \mu \mathrm{m}$ and time of $600 \mathrm{~s}$

(i) Drag without $\varepsilon$ and no interactions
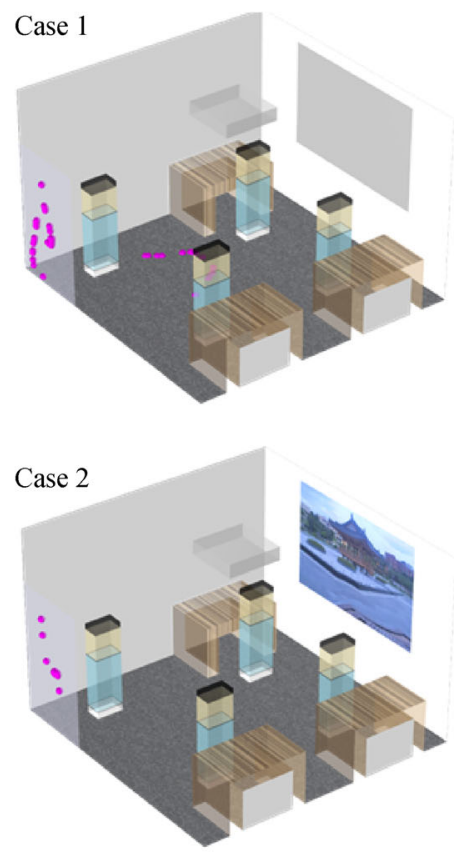

(ii) Drag with $\varepsilon$ and no interactions
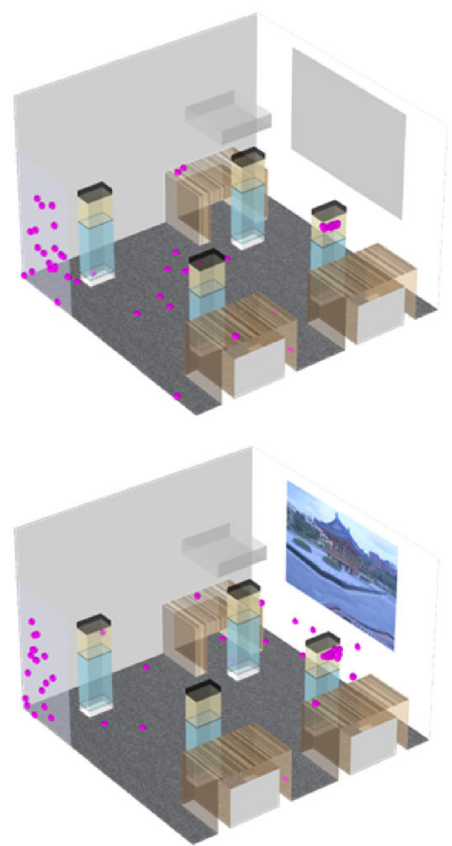

(iii) Drag with $\varepsilon$ and droplet interactions
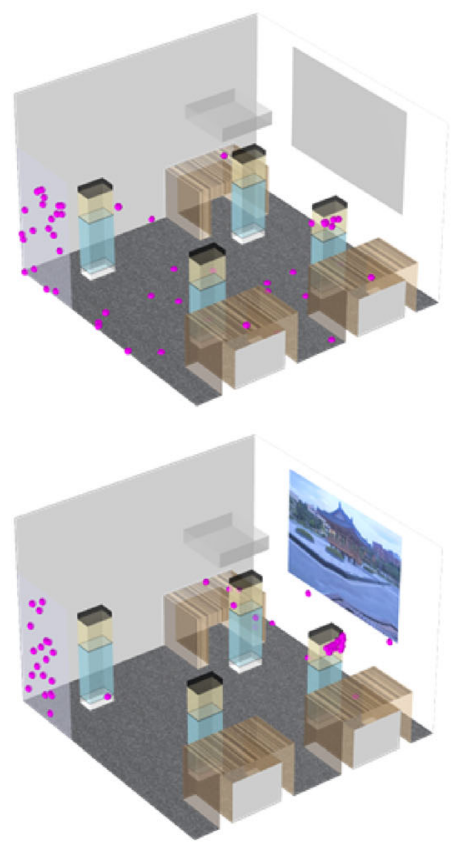

Fig. 5 Fate of $50 \mu \mathrm{m}$ droplets at $600 \mathrm{~s}$ of simulation for Case 1: turned-on ventilator, opened door, and closed window, and Case 2: turned-on ventilator, opened door, and opened window according to modeling approach: (i) drag without $\varepsilon$ and no droplet-droplet interactions, (ii) drag with $\varepsilon$ and no droplet-droplet interactions, (iii) drag with $\varepsilon$ and droplet-droplet interactions. The particles were enlarged for better representation.

the release, the droplet interactions changed the path (e. g. transport) that the droplets follow through time. Consequently, the final position of the droplets on a boundary (e.g. fate) changed. Thus, with the net repulsive interactions the path of the droplets and their final location changed. The droplet fate (iii) considering particle interactions tended to be similar with that in (ii) modeling without droplet interactions (Table 1). However, final locations of the droplets considerably changed due to droplet interactions. It has to be mentioned that droplet interactions will also occur at any moment when droplets encounter at a distance equal or shorter than the specified cut-off distance of $0.9 d_{p}$ (Materials and methods section). Furthermore, it has to be noted that the droplet interactions do not allow full contact between droplet surfaces due to $\sigma_{L J}$ in the Born repulsion which allows a closest approach of $0.6 \mathrm{~nm}$.

When the window was opened (Case 2), the droplet transport slightly decreased and the fate was slightly wider for $1 \mu \mathrm{m}$ droplets. Figure 4 and Table 1 indicate that $10 \%$ less droplets tended to exit through the door when droplet interactions were considered. Conversely, for $50 \mu \mathrm{m}$ droplets (Fig. 5 and Table 1), droplet transport and fate did not significantly changed but final spatial locations did. Additionally, Fig. 5 and Table 1 indicate that only $2 \%$ more droplets exited through the door.
Table 1 suggests that desks, walls and floor in an office should be frequently disinfected to inactivate the virus. It was previously mentioned that SARS $-\mathrm{CoV}-2$ droplets can survive different periods based on the material type where they adhered to (Kampf et al., 2020; van Doremalen et al., 2020). Moreover, previous literature has already reported how different disinfectants inactivate the virus (Kampf et al., 2020; van Doremalen et al., 2020). Additionally, an opened door provided an exit for the droplets. However, the droplets can further exit the office and produce infections in surrounding areas. This, in fact, can be similar to what happened in Hong Kong, China in 2003 during the SARS $-\mathrm{CoV}-1$ when droplets spread inside a building and even nearby buildings, causing new infections (Yu et al., 2004).

Finally, an additional simulation using a droplet diameter of $50 \mu \mathrm{m}$ was conducted in a simplified system to more clearly observe the effects of droplet interactions. For the simulation, a larger diameter was chosen to highlight the droplet transport. Figure 8 presents the results of the additional simulations and two main observations were made. First, effects of $\varepsilon$ on $F_{D}$ tended to increase the distance that the droplets traveled. This was in accordance with Figs. 4 and 5. Second, droplet interactions further increased the travel distance because, in the first seconds of release when the droplets were closer to each other, net 
repulsive droplet interactions (Figs. 6 and 7) tended to repel the droplets from each other. Consequently, droplet velocity and path changed generating different spatial locations over time; note that $\varepsilon$ on $F_{D}$ produced a random motion through time and this random motion changed according to the effects of droplet interactions.

\section{Limitations of the modeling}

The model is sensitive to several variables (office configuration, air velocities, droplet size distribution just after expelling, droplet size distribution during transport and fate, ventilation system, etc.) and a sensitivity study should be conducted. Nevertheless, it was observed that $\varepsilon$ influences the model, specifically, including $\varepsilon$ resulted in wider droplet spreading. Furthermore, since $\varepsilon$ is mesh dependent, any change in mesh will likely to produce different results. Thus, it is preferable to analyze and characterize $\varepsilon$ as proposed in our study. The model should also consider accurate droplet expel kinetics, including a non-linear droplet expelling, and higher droplet concentrations. Additionally, it should be reconsidered to formulate $F_{C}$ in an exponential fashion. This is because, for example, colloids in solutions develop an electrostatic interaction that decays exponentially with distance and there might be a similarity with aerosols. Capillary force, hydrophobic force (contact angle), and Derjaguin, Landau,
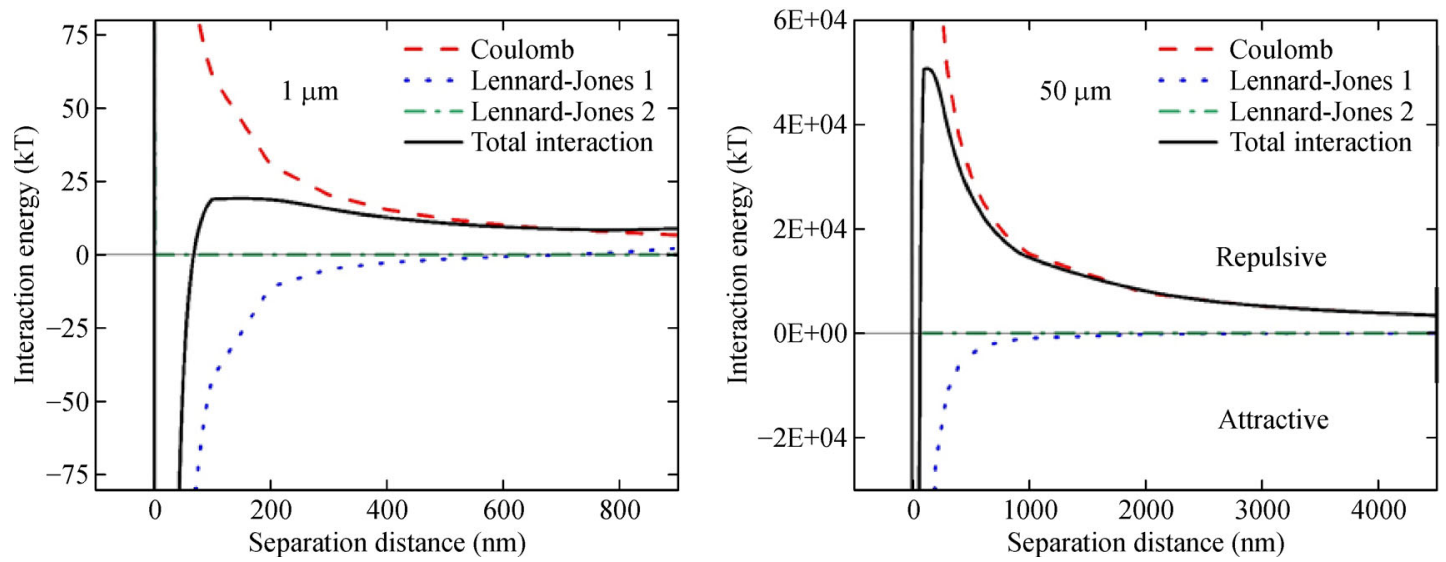

Fig. 6 Interaction energy profiles of 1 and $50 \mu \mathrm{m}$ droplets as a function of separation distance between droplets.

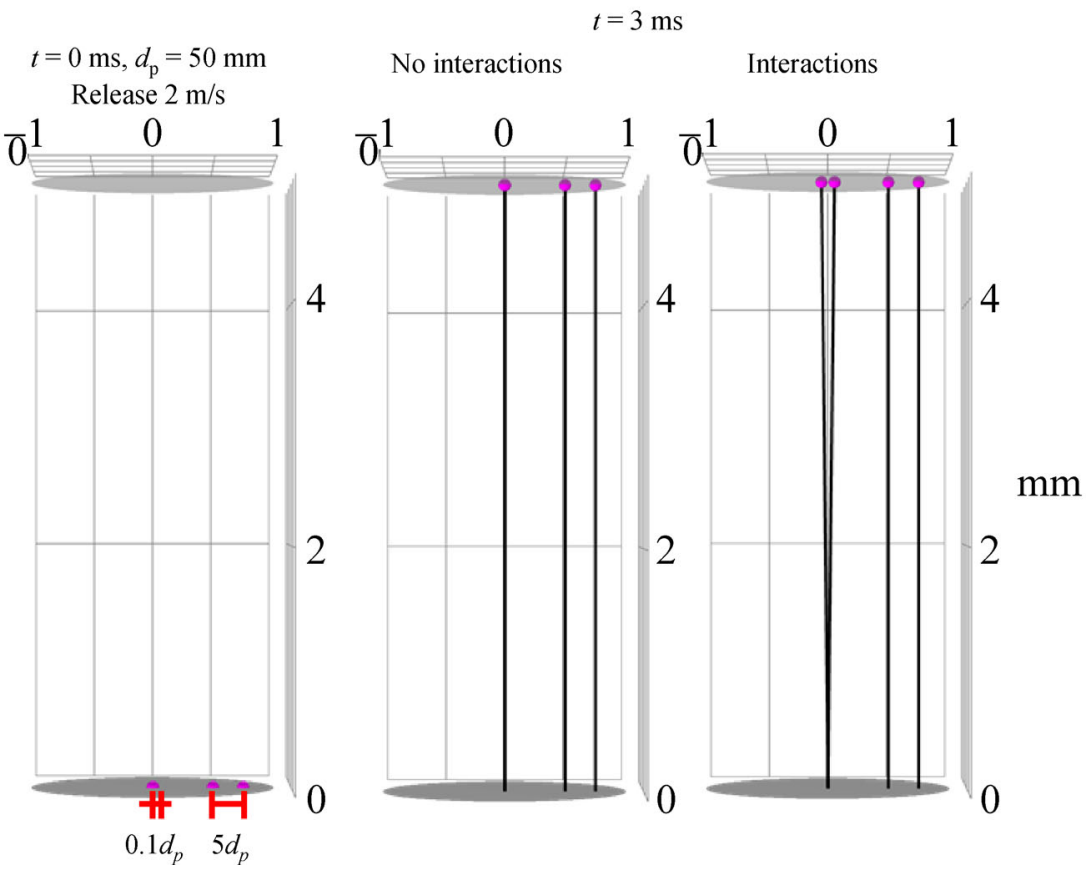

Fig. 7 Control simulation for the path and final position of $50 \mu \mathrm{m}$ droplets at 0 and 3 mili seconds. Drag and turbulence were not considered. The particles were enlarged for better representation. 


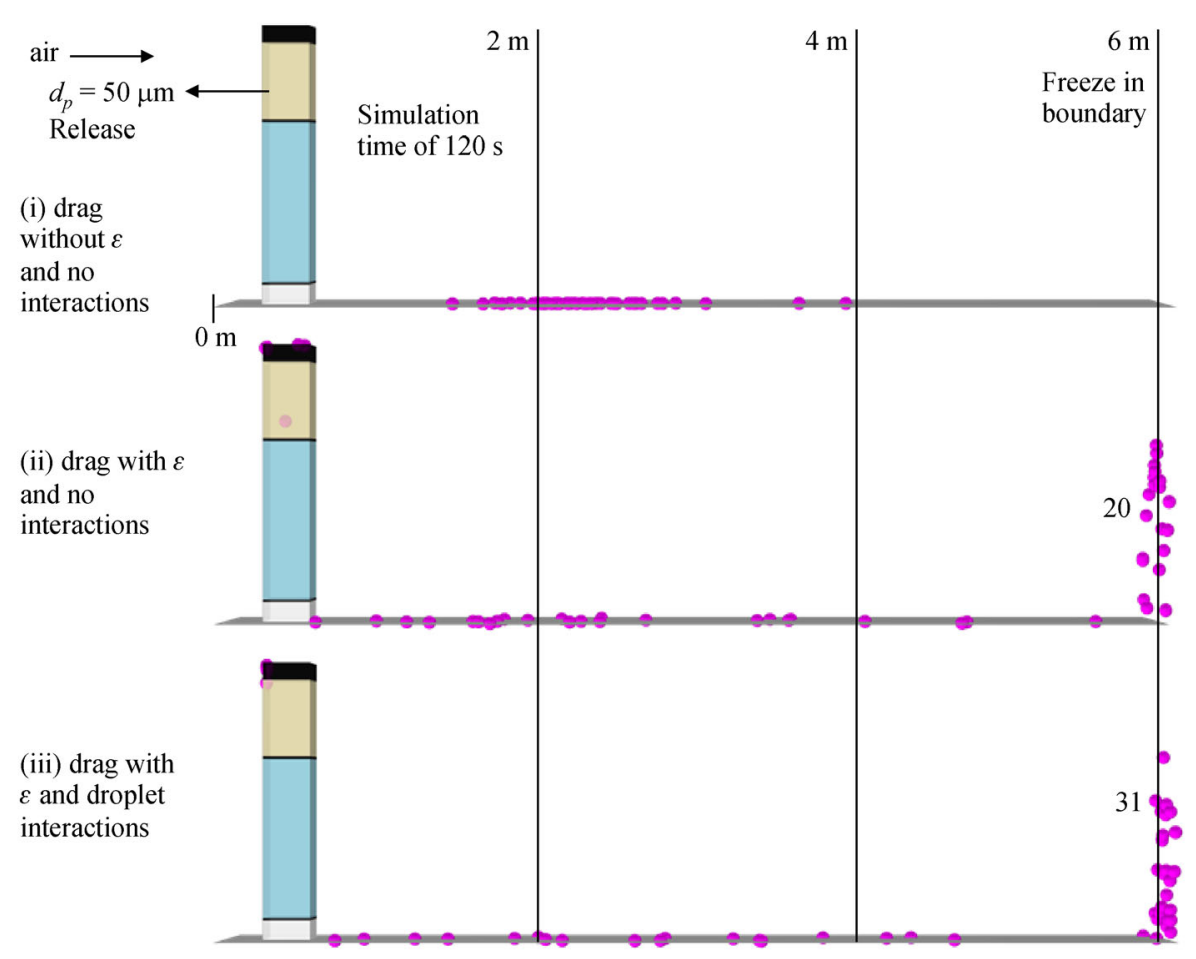

Fig. 8 Control simulation for the transport and fate of $50 \mu \mathrm{m}$ droplets at $120 \mathrm{~s}$ according to the modeling approach. The particles were enlarged for better representation.

Verwey, and Overbeek (DLVO) interactions could also be implemented in future studies. DLVO interactions apply for colloids in water having particle-particle or particle-surface interactions, but their applicability to aerosols is not clear. Further studies considering different droplets sizes, changes in size from aggregation (coalescence) due to capillary forces, and other properties of droplets are required. Finally, evaporation rates and size distribution should also be considered. Furthermore, it is expected that particle - particle interactions could influence the evaporation rates and size distribution.

\section{Conclusions}

A roof ventilation system moves air by mechanical ventilation and creates recirculation spaces inside an office room. Closed windows may result in bad air quality, this can be partially solved by opening a window. Regarding the recommendation from the WHO, opening windows in the workplace has to be carefully evaluated since it may complicate the transport and fate of droplets. Nevertheless, an opened window generated more droplet adhesion to surfaces, more attention can be paid to surface disinfection. More importantly, it was found that net repulsive droplet-droplet interactions influence the transport of droplets and changes their fate by altering their early and final spatial locations. In detail, an opened window decreased the transport of $1 \mu \mathrm{m}$ droplets and increased their spread inside the office. In contrast, an opened window strongly influenced the fate of $50 \mu \mathrm{m}$ droplets by changing their spatial locations inside the office. The effects of droplet interactions have to be carefully evaluated by droplet size. Thus, future studies should also focus on droplet fate, including their spatial distribution for higher accuracy in predicting the droplet contact with people or other surfaces. The scientific contributions and innovative points of the current research are as follows: 1) droplet-droplet interactions were included since other works focused on other physical phenomena (air flow, air temperature, particle evaporation, forces on the particles); 2) deeper investigation of parameters ( $\varepsilon$ and $\eta$ ) for characterizing the turbulence in a ventilated room because it is widely known that turbulence is highly sensitive to mesh resolution in mesh-based modeling. Finally, given that sufficient budget is provided for further research, experimental validation of the air flow, turbulence, droplet-droplet interactions, and transport and fate of droplets provided in our study should be conducted. The results in our study are specific for the system but it provides guidelines of how droplet-droplet interactions are expected to influence the fate and transport.

\section{List of symbols}

$\begin{array}{ll}\mathrm{C}_{D} & \text { Drag coefficient } \\ C_{L} & \text { Lagrangian time scale coefficient } \\ d_{p} & \text { Droplet diameter }\end{array}$




\section{Elementary charge}

Dissipation rate of turbulent kinetic energy

Permittivity of vacuum

Air dynamic viscosity

Kolmogorov's length scale of turbulence

Coulomb force

Drag force

Lennard-Jones force

Particle $i$

Particle $j$

Turbulent kinetic energy

Turbulent dissipation length scale

Particle mass

Particle Reynolds number

Position vector of the $i^{\text {th }}$ particle

Position vector of the $j^{\text {th }}$ particle

Air density

Particle density

Interaction strength

Stokes number

Distance of closest approach between particles

Simulation time

Eddy lifetime

Eddy crossing time

Eddy interaction time

Lagrangian time scale

Particle velocity response time

Averaged air velocity

Air velocity vector

Root mean square of air velocity (Turbulent air velocity perturbation)

Friction velocity of air at wall

Dynamic viscosity of air

Particle velocity

Wall normal direction

Wall lift - off

Particle surface potential $=$ zeta potential

Vector of random numbers

Streamwise direction (parallel) to wall

Spanwise direction (orthogonal to streamwise and normal)

Normal direction to wall

Acknowledgements This work was supported by the Brain Pool Program through the National Research Foundation of Korea (NRF) funded by the Ministry of Science and ICT, Republic of Korea (No. 2019H1D3A 2A02101993).

Conflict of Interest The authors do not have conflicts of interest to declare.

\begin{abstract}
Author Contributions
Allan Gomez-Flores: Methodology, Investigation, Software, Writing Original draft preparation. Gukhwa Hwang: Writing - Original draft preparation. Sadia Ilyas: Writing - Reviewing and Editing. Hyunjung Kim: Conceptualization, Supervision, Writing - Reviewing and Editing.
\end{abstract}

Electronic Supplementary Material Supplementary material is available in the online version of this article at https://doi.org/10.1007/s11783-021$1465-8$ and is accessible for authorized users.

\section{References}

Abe K, Kondoh T, Nagano Y (1994). A new turbulence model for predicting fluid-flow and heat-transfer in separating and reattaching flows. 1. Flow-field calculations. International Journal of Heat and Mass Transfer, 37(1): 139-151

Achebe C H, Omenyi S N (2013). Mathematical determination of the critical absolute Hamaker constant of the serum (as an intervening medium) which favours repulsion in the human immunodeficiency virus (HIV)-blood interactions mechanism. In: Proceedings of the World Congress on Engineering of the Imperial College 2013. London: Newswood Limited, Volume 2, 1380-1384

Asadi S, Bouvier N, Wexler A S, Ristenpart W D (2020). The coronavirus pandemic and aerosols: Does COVID-19 transmit via expiratory particles? Aerosol Science and Technology, 54(6): 635638

Asadi S, Wexler A S, Cappa C D, Barreda S, Bouvier N M, Ristenpart W D (2019). Aerosol emission and superemission during human speech increase with voice loudness. Scientific Reports, 9(1): 2348

Chao C Y H, Wan M P, Morawska L, Johnson G R, Ristovski Z D, Hargreaves M, Mengersen K, Corbett S, Li Y, Xie X, Katoshevski D (2009). Characterization of expiration air jets and droplet size distributions immediately at the mouth opening. Journal of Aerosol Science, 40(2): 122-133

Czub M, Weingartl H, Czub S, He R T, Cao J X (2005). Evaluation of modified vaccinia virus Ankara based recombinant SARS vaccine in ferrets. Vaccine, 23(17-18): 2273-2279

Dehbi A (2008). Turbulent particle dispersion in arbitrary wall-bounded geometries: A coupled CFD-Langevin-equation based approach. International Journal of Multiphase Flow, 34(9): 819-828

Dowell S F, Simmerman J M, Erdman D D, Wu J S J, Chaovavanich A, Javadi M, Yang J Y, Anderson L J, Tong S X, Ho M S (2004). Severe acute respiratory syndrome coronavirus on hospital surfaces. Clinical Infectious Diseases, 39(5): 652-657

Drossinos Y, Stilianakis N I (2020). What aerosol physics tells us about airborne pathogen transmission. Aerosol Science and Technology, 54 (6): 639-643

Gao N P, Niu J L (2006). Transient CFD simulation of the respiration process and inter-person exposure assessment. Building and Environment, 41(9): 1214-1222

Gao N P, Niu J L, Morawska L (2008). Distribution of respiratory droplets in enclosed environments under different air distribution methods. Building Simulation, 1(4): 326-335

Gentile G J, Cruz M C, Rajal V B, Fidalgo de Cortalezzi M M F (2018). Electrostatic interactions in virus removal by ultrafiltration membranes. Journal of Environmental Chemical Engineering, 6(1): 1314- 
1321

Gomez-Flores A, Bradford S A, Hwang G, Heyes G W, Kim H (2020). Particle-bubble interaction energies for particles with physical and chemical heterogeneities. Minerals Engineering, 155(1): 106472

Haas F C (1964). Stability of droplets suddenly exposed to a high velocity gas stream. AIChE Journal. American Institute of Chemical Engineers, 10(6): 920-924

Hagenaars N, Mastrobattista E, Verheul R J, Mooren I, Glansbeek H L, Heldens J G M, Van Den Bosch H, Jiskoot W (2009). Physicochemical and immunological characterization of N,N,N-trimethyl chitosan-coated whole inactivated influenza virus vaccine for intranasal administration. Pharmaceutical Research, 26(6): 13531364

He Q B, Niu J L, Gao N P, Zhu T, Wu J Z (2011). CFD study of exhaled droplet transmission between occupants under different ventilation strategies in a typical office room. Building and Environment, 46(2): 397-408

He Y X, Zhou Y S, Siddiqui P, Jiang S B (2004). Inactivated SARS-CoV vaccine elicits high titers of spike protein-specific antibodies that block receptor binding and virus entry. Biochemical and Biophysical Research Communications, 325(2): 445-452

Isella L, Drossinos Y (2010). Langevin agglomeration of nanoparticles interacting via a central potential. Physical Review. E, 82(1): 011404

Joshi J B, Nere N K, Rane C V, Murthy B N, Mathpati C S, Patwardhan A W, Ranade V V (2011). CFD simulation of stirred tanks: Comparison of turbulence models. Part I: Radial flow impellers. Canadian Journal of Chemical Engineering, 89(1): 23-82

Kampf G, Todt D, Pfaender S, Steinmann E (2020). Persistence of coronaviruses on inanimate surfaces and their inactivation with biocidal agents. Journal of Hospital Infection, 104(3): 246-251

Kao P H, Yang R J (2006). Virus diffusion in isolation rooms. Journal of Hospital Infection, 62(3): 338-345

Katopodes N D (2019). Free-surface flow: environmental fluid mechanics.Kidlington: Butterworth-Heinemann, 1 online resource

Khachatourian A V, Wistrom A O (2001). Size effects in aerosol electrostatic interactions. Journal of Colloid and Interface Science, 242(1): $52-58$

Liu X, Zhai Z Q (2007). Identification of appropriate CFD models for simulating aerosol particle and droplet indoor transport. Indoor and Built Environment, 16(4): 322-330

Liu Y, Ning Z, Chen Y, Guo M, Liu Y, Gali N K, Sun L, Duan Y, Cai J, Westerdahl D, Liu X, Ho K F, Kan H, Fu Q, Lan K (2020). Aerodynamic characteristics and RNA concentration of SARS-CoV2 aerosol in two hospitals during COVID-19 outbreak. bioRxiv, 2020: 2020.2003.2008.982637

Ma C Q, Li Y, Wang L L, Zhao G Y, Tao X R, Tseng C T K, Zhou Y S, Du L Y, Jiang S B (2014). Intranasal vaccination with recombinant receptor-binding domain of MERS-CoV spike protein induces much stronger local mucosal immune responses than subcutaneous immunization: Implication for designing novel mucosal MERS vaccines. Vaccine, 32(18): 2100-2108

Matida E A, Finlay W H, Lange C F, Grgic B (2004). Improved numerical simulation of aerosol deposition in an idealized mouththroat. Journal of Aerosol Science, 35(1): 1-19

Minier J P (2015). On Lagrangian stochastic methods for turbulent polydisperse two-phase reactive flows. Progress in Energy and
Combustion Science, 50: 1-62

Mofakham A A, Ahmadi G (2020). On random walk models for simulation of particle-laden turbulent flows. International Journal of Multiphase Flow, 122(1): 103157

Mui K W, Wong L T, Wu C L, Lai A C K (2009). Numerical modeling of exhaled droplet nuclei dispersion and mixing in indoor environments. Journal of Hazardous Materials, 167(1-3): 736-744

Nguyen A V, An-Vo D A, Tran-Cong T, Evans G M (2016). A review of stochastic description of the turbulence effect on bubble-particle interactions in flotation. International Journal of Mineral Processing, 156: $75-86$

Ong S W X, Tan Y K, Chia P Y, Lee T H, Ng O T, Wong M S Y, Marimuthu K (2020). Air, surface environmental, and personal protective equipment contamination by severe acute respiratory syndrome coronavirus 2 (SARS-CoV-2) from a symptomatic patient. Journal of the American Medical Association, 323(16): $1610-1612$

Park D Y, Chang S (2019). Numerical investigation of thermal comfort and transport of expiratory contaminants in a ventilated office with an air curtain system. Indoor and Built Environment, 28(3): 401-421

Praskievicz S, Chang H J (2009). Identifying the relationships between urban water consumption and weather variables in Seoul, Republic of Korea. Physical Geography, 30(4): 324-337

Redrow J, Mao S L, Celik I, Posada J A, Feng Z G (2011). Modeling the evaporation and dispersion of airborne sputum droplets expelled from a human cough. Building and Environment, 46(10): 2042-2051

Santarpia J L, Rivera D N, Herrera V L, Morwitzer M J, Creager H M, Santarpia G W, Crown K K, Brett-Major D M, Schnaubelt E R, Broadhurst M J, Lawler J V, Reid S P, Lowe J J (2020). Aerosol and surface contamination of SARS-CoV-2 observed in quarantine and isolation care. Scientific Reports, 10(1): 12732

Shang W L, Yang Y, Rao Y F, Rao X C (2020). The outbreak of SARSCoV-2 pneumonia calls for viral vaccines. NPJ Vaccines, 5(1): 18

Squires P (1958). The microstructure and colloidal stability of warm clouds. 2 . The causes of the variations in microstructure. Tellus, 10 (2): 262-271

Stadnytskyi V, Bax C E, Bax A, Anfinrud P (2020). The airborne lifetime of small speech droplets and their potential importance in SARS-CoV-2 transmission. Proceedings of the National Academy of Sciences of the United States of America, 117(22): 11875-11877

Sun W, Ji J (2007). Transport of droplets expelled by coughing in ventilated rooms. Indoor and Built Environment, 16(6): 493-504

Thomson D J (1987). Criteria for the selection of stochastic-models of particle trajectories in turbulent flows. Journal of Fluid Mechanics, 180(1): 529-556

van Doremalen N, Bushmaker T, Morris D H, Holbrook M G, Gamble A, Williamson B N, Tamin A, Harcourt J L, Thornburg N J, Gerber S I, Lloyd-Smith J O, de Wit E, Munster V J (2020). Aerosol and surface stability of SARS-CoV-2 as compared with SARS-CoV-1. New England Journal of Medicine, 382(16): 1564-1567

Vohra K G, Nair P V N (1971). Stability of submicron aqueous solution droplets in the atmosphere. Journal of the Atmospheric Sciences, 28 (2): $280-285$

Walls A C, Park Y J, Tortorici M A, Wall A, Mcguire A T, Veesler D (2020). Structure, function, and antigenicity of the SARS-CoV-2 spike glycoprotein. Cell, 181(2): 281-292.e6 
Wang L S, Shi W, Joyce M G, Modjarrad K, Zhang Y, Leung K, Lees C R, Zhou T Q, Yassine H M, Kanekiyo M, Yang Z Y, Chen X J, Becker M M, Freeman M, Vogel L, Johnson J C, Olinger G, Todd J P, Bagci U, Solomon J, Mollura D J, Hensley L, Jahrling P, Denison M R, Rao S S, Subbarao K, Kwong P D, Mascola J R, Kong W P, Graham B S (2015). Evaluation of candidate vaccine approaches for MERS-CoV. Nature Communications, 6(1): 7712

W.H.O. (2020). Getting your workplace ready for COVID-19: How COVID-19 spreads? Geneva: World Health Organization (WHO)

Wu J, Ping Z (2020). Association of COVID-19 disease severity with transmission routes and suggested changes to community guidelines. Preprints, 2020:202003.0246.v1

Xie X J, Li Y G, Sun H Q, Liu L (2009). Exhaled droplets due to talking and coughing. Journal of the Royal Society, Interface, 6(suppl_6): S703-S714

Yan W, Zhang Y H, Sun Y G, Li D N (2009). Experimental and CFD study of unsteady airborne pollutant transport within an aircraft cabin mock-up. Building and Environment, 44(1): 34-43

Yu I T S, Li Y G, Wong T W, Tam W, Chan A T, Lee J H W, Leung D Y $\mathrm{C}$, Ho T (2004). Evidence of airborne transmission of the severe acute respiratory syndrome virus. New England Journal of Medicine, 350 (17): 1731-1739

Zhang H, Li D, Xie L, Xiao Y (2015). Documentary research of human respiratory droplet characteristics. Procedia Engineering, 121: 13651374

Zhu S W, Kato S, Yang J H (2006). Study on transport characteristics of saliva droplets produced by coughing in a calm indoor environment. Building and Environment, 41(12): 1691-1702

Zhu S W, Srebric J, Spengler J D, Demokritou P (2012). An advanced numerical model for the assessment of airborne transmission of influenza in bus microenvironments. Building and Environment, 47: 67-75 